FERNANDO ANTÔNIO AZEVEDO

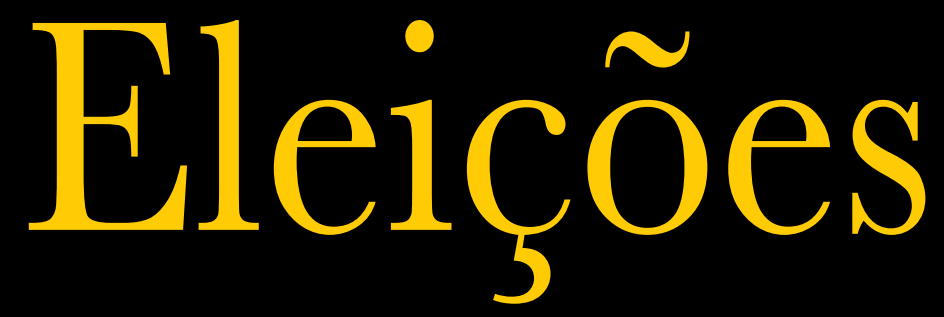

presidenciais,

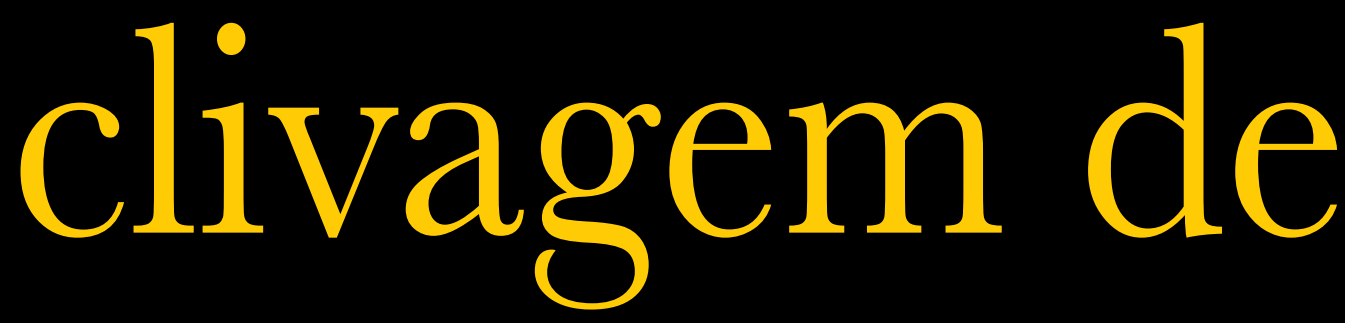

classe e 
FERNANDO

ANTÔNIO AZEVEDO

é professor associado

da Universidade

Federal de São Carlos

(UFSCar).

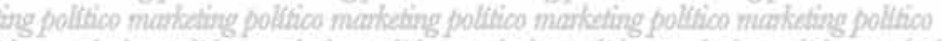

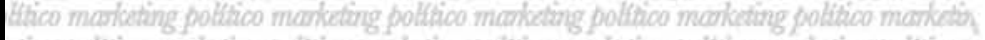

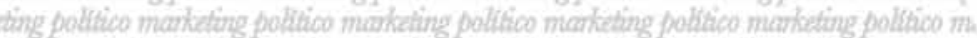

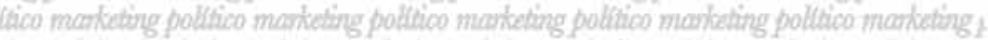

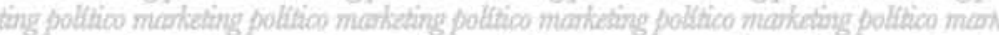

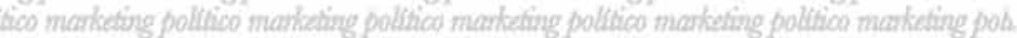

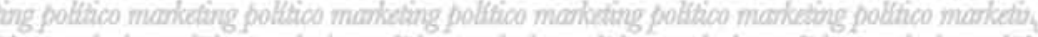

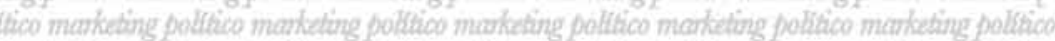

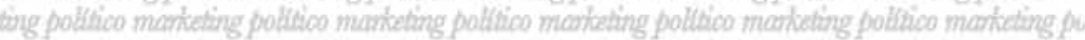

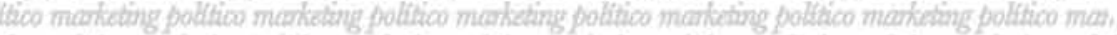

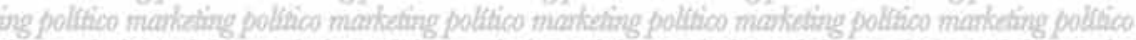

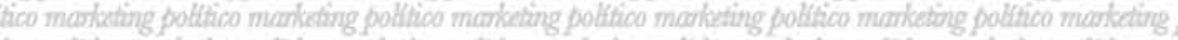

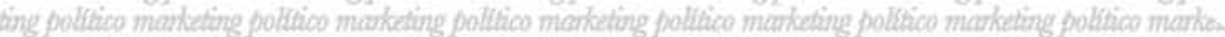

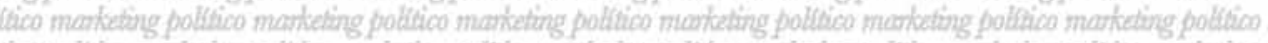

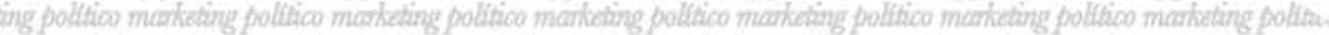

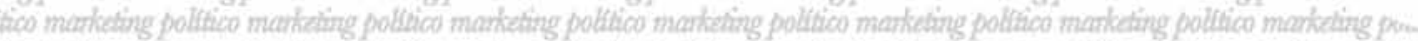

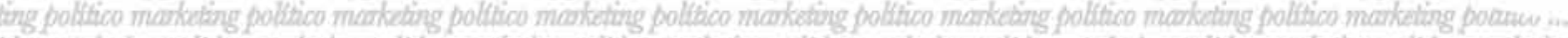

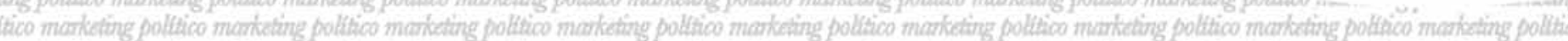

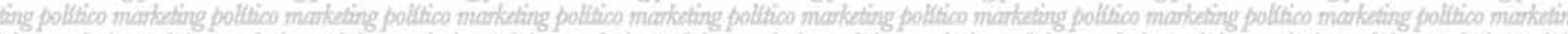

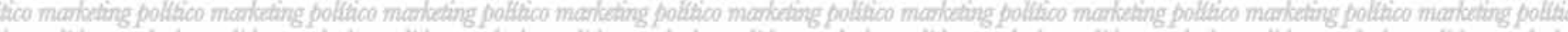

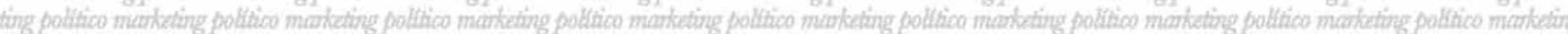

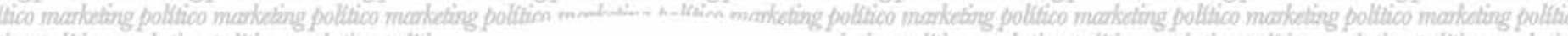

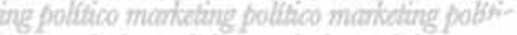

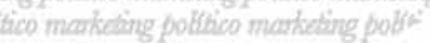

ing polthico moanketing polltico or

Thico markicking polltico mar

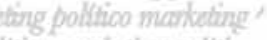

Wico mariketing polty'

Ging pollitico mat' Rico marilation Cing polltich Wico mat to f f
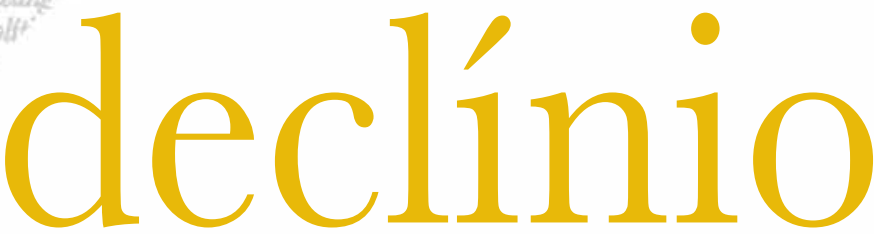

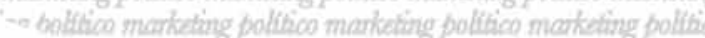
- nolltico manketing politioo markating pottico markedin sing politico maxheling polltico marketing politi.

ting poltivoo marketing político mankedir.

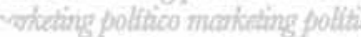
nakeding politico mankedir. Titico markoting politit solitico manketer reling politi That:
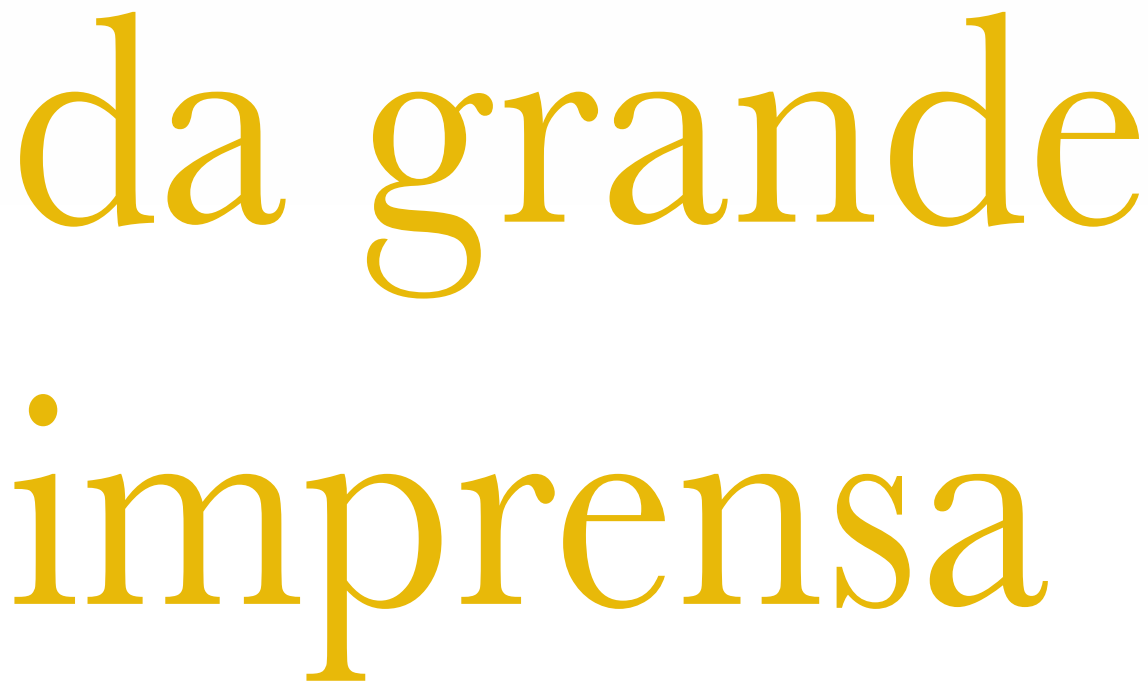


\title{
RESUMO
}

O artigo faz um balanço das eleições presidenciais de 2006 e 2010 tendo como foco analítico três dimensões: as estratégias de campanha, a cobertura da grande imprensa escrita e o comportamento do eleitor. A partir dessas dimensões, discute os resultados eleitorais, a agenda-setting do processo eleitoral e a influência da mídia para argumentar que, nesses dois pleitos: 1) houve um descolamento entre a agenda política da classe $A B$ e a chamada "nova classe média"eos"pobres";2) ovoto foi predominantemente"governista", estruturado por uma clivagem de classe e orientado pelo voto pragmático e retrospectivo; e, finalmente, 3) que a influência da grande imprensa escrita ficou restrita às classes $A B$, que constituem seu público leitor por excelência e as principais parcelas do eleitorado oposicionista.

Palavras-chave: eleições, campanha, mídia, comunicação política.

\begin{abstract}
This article presents an account of the presidential elections of 2006 and 2010; and an analysis divided into three focuses: the campaign strategies, the coverage by the mainstream written press, and the behavior of voters. From those viewpoints, it discusses the election results, the agenda-setting of the election process, and media influence; so as to argue that in those two ballots, 1) there was a detachment between the political agenda of the $A$ and $B$ classes $B$ and the so-called "new middle class" and the "poor"; 2) voting was predominantly "pro-government" and structured by a class cleavage, and oriented towards a retrospective and pragmatic vote and finally, 3) the influence of the mainstream written press was restricted to the $A$ and $B$ classes - which make up its reading audience par excellence - and the main blocs of the oppositionist body of voters.
\end{abstract}

Keywords: elections, campaign, media, political communication. 
política nacional desenrola-se num quadro de absoluta estabilidade ao longo dos últimos dezesseis anos.

Desde a vitória de FHC, em 1994, ano que podemos considerar como uma "eleição crítica" para o realinhamento eleitoral do nosso sistema partidário (Mettenhein, 2003,p. 246), as eleições presidenciais são polarizadas entre tucanos e petistas, que lideram amplas coalizões eleitorais e dão ao nosso sistema partidário uma lógica, pelo menos no que diz respeito à disputa presidencial, de uma competição bipartidária. Essa polarização eleitoral pode ser definida como moderada (Sartori, 1983) do ponto de vista ideológico, pois, apesar das origens partidárias e bases sociais distintas, diferenças programáticas e de estilo e práticas políticas, ambos os partidos ocupam o centro da política brasileira, um com viés à esquerda, outro com viés à direita.

Apesar da estabilidade no padrão de disputa eleitoral, o comportamento do eleitorado tem passado por mudanças significativas nos últimos dois pleitos presidenciais. Duas dessas mudanças são notáveis e estão interligadas.

A primeira, a discrepância entre o voto dos "ricos" e dos "pobres", como chama atenção Lavareda (2009, p. 91). Segundo o autor, considerando-se a distribuição de votação das eleições presidenciais, entre 1989 e 2006, e levando-se em conta os diferentes estratos de renda e educação ${ }^{1}$, há uma relativa homogeneidade do voto entre 1994 e 2002, e discrepância nos pleitos de 1989 e 2006. Em 1989, como sabemos, a disputa foi marcada por uma forte clivagem ideológica entre a esquerda e a direita, tendo ainda por pano de fundo o antigo cenário do embate entre o socialismo e o capitalismo. A segunda discrepância, em 2006, se deu dentro do quadro de estabilidade descrito no primeiro parágrafo, ou seja, dentro da dinâmica de uma disputa polarizada entre o PT e o PSDB, com ambos os partidos disputando o eleitorado do centro político e, portanto,

Uma das formas adotadas para classificar os estratos sociais é o "Critério Brasil" que, considerando a posse de bens de consumo e a escolaridade do chefe de familia, divide a população em classes de $A$ a $E$, sendo a classe $\mathrm{C}$ comumente considerada como classe média. Uma classificação alternativa toma a renda familiar como parâmetro. Nesse caso, as classes A e B são as unidades familiares que ganham mais de dez salários mínimos, a C, de três a dez, e a classe E, abaixo desse valor. 
2 Usamos aqui o termo "clivagem política" no sentido utilizado por Rae e Taylor (1970), ou seja, que toda opinião tende a cindir-se sobre escolhas alternativas que são propostas pelos partidos criando, assim divisões duráveis (clivagens) Essas clivagens, obviamente, podem ser de classe, regionais, religiosas, linguísticas, etc. dentro de uma lógica de confronto em que a clivagem ideológica não era mais relevante. Porém, como todos podem recordar, a campanha eleitoral de 2006 foi uma das mais cruentas por conta do chamado "escândalo do mensalão", largamente explorado pela oposição e pela grande imprensa, que em quase sua totalidade se posicionou contra a recondução do presidente Lula. Finalmente, podemos acrescentar uma terceira discrepância no pleito de 2010, no qual as classes alta e média tradicional (os estratos de renda $\mathrm{AB}$ ) votaram preferencialmente no candidato tucano e os demais estratos, na candidata petista.

A segunda mudança no comportamento do eleitor diz respeito à dissociação entre o resultado eleitoral e a posição editorial assumida pela maioria dos veículos da chamada grande imprensa escrita (que também chamarei indistintamente, aqui, de mídia tradicional ou grandes jornais), formada pelos jornais de circulação nacional ( $O$ Estado de S .Paulo, a Folha de S. Paulo, $O$ Globo) e revistas informativas semanais (Veja, Época, IstoÉ e Carta Capital). A mídia tradicional,nessa quadra democrática que se iniciou em 1985, apoiou em todas as disputas presidenciais os candidatos antipetistas (casos do Estadão,O Globo e da Veja) ou, ainda que se declarando partidariamente neutro (como a Folha de S. Paulo), assumiu forte posição crítica contra as candidaturas petistas (Azevedo, 2008). A única exceção na postura da mídia nessas sequências de eleições presidenciais foi em 2002, quando a campanha petista deslocou-se para o centro político, assumindo um tom moderado (precedida pela “Carta aos Brasileiros", em junho daquele ano, comprometendo-se em manter a estabilidade econômica e fiscal e os contratos internacionais), e o governo FHC enfrentou um forte desgaste perante a opinião pública. Considerando-se as cinco eleições presidenciais, houve convergência entre a orientação editorial da maioria da mídia tradicional e os resultados eleitorais em 1989 (eleição de Collor), 1994 e 1998 (FHC). Em 2002, como já assinalado, foi um ano atípico. $\mathrm{E}$ nos dois últimos pleitos, em 2006 e 2010, houve uma dissociação entre a vontade dos eleitores e a posição editorial da maioria dos jornais e revistas da grande imprensa.

Confrontando as séries de dados referentes ao voto dos "ricos" $x$ "pobres" e orientação editorial predominante na grande imprensa $x$ resultados eleitorais, constatamos que as discrepâncias ocorrem simultaneamente apenas nas duas últimas eleições, ou seja, 2006 e 2010. A partir dessa constatação cabe perguntar se os dois últimos resultados eleitorais:

a) significam a existência de uma nova divisão eleitoral nas eleições presidenciais baseada numa clivagem de classe ${ }^{2}$;

b) indicam que a grande imprensa escrita perdeu a capacidade de influenciar o conjunto do eleitorado a partir dos formadores de opinião situados nos estratos mais altos de renda e educação.

\section{TABELA 1}

\section{Intenção de voto [\%] por estrato de renda.}

Eleição presidencial 2010

\begin{tabular}{|l|c|c|c|c|}
\hline Candidatos/renda & Até 2 SM & De 2 a 5 SM & $\begin{array}{c}\text { De 5 a 10 } \\
\text { SM }\end{array}$ & + 10 SM \\
\hline Dilma & 53 & 43 & 37 & 31 \\
\hline Serra & 26 & 31 & 34 & 38 \\
\hline
\end{tabular}


Para responder à segunda questão será necessário tomar a primeira como ponto de partida. $O$ artigo assume a premissa inicial de que há uma nova divisão eleitoral produzida basicamente pelo: a) impacto político nos segmentos de baixa renda das políticas sociais do governo Lula (especialmente o Bolsa Família) e; b) a grande mobilidade social que, a partir da década passada, deslocou cerca de 29 milhões de brasileiros da base da pirâmide social em direção à classe $\mathrm{C}$, originando o que Neri (2010) definiu como "nova classe média". Esses dois segmentos ("pobres" e a "nova classe média") têm aspirações e demandas que, durante o governo Lula, se estruturam numa agenda própria dissociada das prioridades da agenda da classe alta e média tradicional $(\mathrm{AB})$ cuja opinião costuma ser formada, expressa ou reverberada na e pela grande mídia.

A partir desses pressupostos, o artigo sustentará a hipótese de que:

1) a maioria do eleitorado mais "pobre" e a "nova classe média", em 2006 e 2010, votaram de forma pragmática levando em conta as prioridades das suas agendas (redistribuição de renda e mobilidade social) em detrimento da agenda das classes AB, fundada na questão ética, accountability, eficiência gerencial, e o debate sobre o papel do Estado. Esse voto, sugere Carlos Zucco (2006), foi essencialmente "governista", mas, acrescentaríamos, estruturado através de uma clivagem de classe na qual a orientação do voto esteve fortemente correlacionada com renda e educação e o voto pragmático e retrospectivo;

2) por conta da dissociação entre as agendas da classe AB e as demais, a grande imprensa, orientada historicamente para a elite política, econômica e intelectual, perdeu, nas duas últimas eleições presidenciais, o papel decisivo que desempenhou, através dos “formadores de opinião", na orientação do voto nos processos eleitorais do passado. A sua influência nos dois últimos pleitos presidenciais se restringiu ao seu público leitor, constituído pelas classes $\mathrm{AB}$, como propõe Mundim (2011).

\section{CONCEITOS E REFERÊNCIAS}

\section{TEÓRICAS}

Thomas Holbrook (1966), em seu conhecido livro sobre as campanhas políticas, propõe que três variáveis são fundamentais para entender o processo eleitoral: a situação nacional, os eventos de campanha e a cobertura da mídia. A variável situação nacional abrange as condições econômicas e sociais do país na quadra em que se realiza a competição eleitoral. Como eventos de campanha, Holbrook, que elaborou seu modelo de análise baseado nas eleições americanas, cita as convenções partidárias e os debates eleitorais, eventos que, no caso americano, ganham grande interesse da mídia e dos eleitores. Em relação à mídia, o autor considera que ela é responsável não só pela divulgação e cobertura dos eventos de campanha, como também por veicular a agenda de debates entre os candidatos e seus apoiadores ao mesmo tempo em que lança temas e questões para o debate nacional.

O modelo de Holbrook tem a vantagem de permitir descrever e analisar cada variável de forma independente e depois ponderá-las para interpretar o processo eleitoral em seu conjunto. Para o caso brasileiro, como sugere Borba (2008), é necessário fazer adaptações por conta das características do nosso processo eleitoral, e, de modo pertinente, incluir nos eventos de campanha oHorário Gratuito de Propaganda Eleitoral (HGPE), de importância capital nas campanhas brasileiras, relativizando as convenções partidárias, que não possuem grande impacto de mídia ou eleitoral entre nós. O esquema analítico sugerido por Holbrook é utilizado aqui para estruturar sequencialmente as seções em que este artigo está dividido.

Em relação à variável "campanhas eleitorais", Figueiredo, Aldé, Dias e Jorge (1998) propuseram um modelo bastante funcional para analisar especificamente a estrutura da competição retórica em eleições majoritárias em contextos bipartidários ou em sistemas eleitorais multipartidários po- 
larizados por dois partidos. Para os autores, as campanhas trabalham com a construção de "mundos possíveis" divididos em dois tempos, um atual e outro futuro. Dentro dessa estrutura, para a situação o mundo atual deve ser necessariamente "bom" e o mundo futuro "melhor" enquanto, para a oposição, esses mundos devem ser, respectivamente, "ruim" e "bom". Esse modelo de análise das estratégias comunicativas é particularmente útil para analisar como a situação e a oposição estruturaram suas estratégias retóricas nas duas últimas eleições presidenciais brasileiras.

Quanto ao comportamento do eleitor frente às estratégias de campanha, parte relevante da literatura sobre as preferências eleitorais enfatiza a importância do "voto econômico". Em resumo, essa literatura endossa a afirmação de Lewis-Beck (1988, p. 183) de que os bons tempos mantêm os partidos no poder, os maus tempos expulsam-nos. Em outras palavras, o eleitor recompensa ou pune o governo pela sua performance econômica levando em conta o que Holbrook chamou de "situação nacional", ou seja, os dados macroeconômicos (crescimento da economia, inflação, emprego, renda, etc.) ou a sensação pessoal de que está melhorando ou piorando de vida. O mecanismo básico dessa escolha eleitoral é o voto "retrospectivo" (Dows, 1957; Key, 1967; Fiorina, 1981), em que o eleitor toma suas decisões eleitorais considerando primariamente o seu bem-estar no presente ("mundo atual") e, portanto, em última análise, o desempenho do governo em exercício em propiciar ou não melhores condições de vida. Nesse sentido, o voto retrospectivo é um passo instrumental para o cálculo do “mundo futuro", ou seja, o voto prospectivo em que o eleitor calcula o que o político ou o partido poderá fazer no poder.

Finalmente, a literatura mais recente sobre o papel da mídia nos processos políticos e eleitorais e na formação da opinião pública atribui aos meios de comunicação um lugar central na produção e circulação de valores e informações políticas nas modernas democracias de massa, caracterizadas por Manin (1995) como “democracias de público".
Entre suas características encontram-se a perda da exclusividade dos partidos na mediação política, a presença cada vez maior de um eleitorado sem vínculos ou fidelidade partidária (podendo gerar, como efeito, volatilidade eleitoral), o deslocamento parcial do debate político para a mídia, a relação direta entre os líderes e o eleitorado (via mídia) e a personalização do processo político-eleitoral. Nesse contexto, em queo eleitor tenderia a votar contingencialmente em função das questões e temas em jogo em cada episódio eleitoral, a mídia assume um papel estratégico devido a sua capacidade de definir agendas públicas (McCombs, 2010).

Por sua vez, Mancini (2011) acredita que, com a disseminação da Internet e as novas mídias sociais (blogs, Facebook, Twitter, etc.), está ocorrendo, nos últimos anos, nas democracias ocidentais, um processo acelerado de fragmentação da mídia e da audiência. Nesse contexto, o consumo da mídia tradicional diminui e o consumo das novas mídias aumenta, e um dos efeitos decorrentes desse fenômeno é a perda da universalidade do público, que tende a se estruturar em nichos a partir de preferências ideológicas, políticas e culturais. Esse processo, se, por um lado, democratiza a informação, por outro, estaria ameaçando o jornalismobaseado na ideia da objetividade (e dirigido para um público universal) e levando a uma "partidarização" da notícia (Mancini cita, como exemplo dessa tendência, a Fox News, cuja programação é orientada para o público conservador).

\section{A SITUAÇÃO NACIONAL (2006E 2010)}

\section{Antecedentes}

Os dois governos de FHC (1995 a 2002) foram marcados pela agenda das reformas do Estado, especialmente a previdenciária e a administrativa (Abrúcio \& Loureiro, 2002), e por duas diretrizes básicas que 
orientaram as políticas públicas produzidas no período: estabilidade macroeconômica (Plano Real e Lei de Responsabilidade Fiscal) e abertura para o mercado através de uma política de privatização (telecomunicações, estrada, energia e quebra do monopólio do petróleo) e um novo tipo de intervenção do Estado através da criação das agências regulatórias. No plano social, o governo FHC criou uma rede de proteção social composta por doze programas com condicionalidades e focalização, entre os quais o Bolsa Escola, Bolsa Alimentação, Auxílio Gás, etc., que depois seriam redefinidos e unificados no programa Bolsa Família no governo Lula.

O segundo mandato FHC (1999-2002) foi marcado por uma conjuntura internacional adversa e por uma grande instabilidade econômica, com a piora de todos os indicadores da economia (exceto inflação). O quadro da situação daquele momento mostra um crescimento abaixo da média histórica, especulação cambial, endividamento crescente do setor público e um déficit em transação corrente na casa de uma centena de bilhões de dólares. O governo se viu forçado a pedir apoio às agências internacionais e implementou o receituário básico do FMI: desvalorização cambial, aumento das taxas básicas dos juros, controle das contas públicas, entre outras medidas que produziram odesaquecimento da economia, o aumento das tensões com os movimentos sociais e um forte desgaste da popularidade do governo, inclusive nas classes médias, onde o governo tinha sua principal base de apoio eleitoral.

A primeira eleição de Lula se deu nessa conjuntura favorável à oposição, e a sua vitória refletiu, antes de qualquer outra coisa, a disposição do eleitorado em mudar e experimentar uma nova alternativa política. Com a disputa polarizada pelas coligações lideradas pelo PT e pelo PSDB e a ausência de uma terceira força eleitoralmente viável, a campanha de Lula explorou o sentimento oposicionista predominante, apostando no tema da mudança política com segurança através de uma campanha orientada para o centro político e centrada na biografia do candidato, crescimento econômico e políticas sociais. A caução política foi a "Carta aos Brasileiros", lançada para neutralizar o comportamento especulativo do mercado financeiro diante do favoritismo de Lula, na qual o candidato se comprometia em manter a estabilidade econômica e os compromissos internacionais assinados pelo governo FHC.

\section{A situação nacional em 2006}

O primeiro governo Lula teve que lidar com os problemas acumulados do governo anterior e, nessa circunstância, optou por manter uma política econômica ortodoxa vista, por diversos críticos, como uma continuidade da gestão FHC. O problema era como conciliar o controle das contas públicas com as promessas de campanha de fortalecimento e ampliação do mercado interno,recuperação do emprego e do salário e a implementação de políticas sociais para reduzir a miséria e as desigualdades sociais.

A opção foi, no primeiro ano, priorizar a estabilidade econômica e encaminhar uma agenda de reformas parciais (previdenciária, tributária e judiciária), todas concluídas em 2003. A partir desse ano, com a melhora do cenário internacional,os indicadores econômicos começam a se recuperar e o governo, embora mantendo a condução econômica ortodoxa, redefine as políticas governamentais para uma perspectiva desenvolvimentista (a partir do mercado interno) e social. O programa Fome Zero ganha uma posição estratégica nesse novo modelo na expectativa de que gerasse um ciclo virtuoso entre investimento e consumo pelo aumento do poder aquisitivo das famílias beneficiadas. Esse programa, logo depois incorporado pelo Bolsa Família (que unificou os programas sociais existentes no governo anterior), gerou um processo de transferência direta de renda, que produziu forte impacto nas regiões metropolitanas e cidades médias com altos índices de desemprego, decorrente da política de estabilização, e nas cidades pequenas da área rural, onde persistiam bolsões de miséria e pobreza. 
TABELA 2

Gasto e beneficiários do programa Bolsa Família

\begin{tabular}{|l|c|c|}
\hline Ano & Gasto (bilhões de reais) & $\begin{array}{c}\text { Nobeneficiários } \\
\text { (milhões de famílias) }\end{array}$ \\
\hline Out./2003 & 3,4 & 3,6 \\
\hline 2004 & 5,7 & 8,7 \\
\hline 2005 & 6,4 & 8,7 \\
\hline
\end{tabular}

Fonte: Almeida Filho e Rosa de Souza (2006, p. 14)

Como se pode ver na Tabela 2 , os investimentos no programa foram crescentes a partir de 2003, ampliando em 2,4 vezes o número de beneficiários até o ano anterior às eleições de 2006. Além do Bolsa Família, o governo criou outros programas sociais com grande impacto em clientelas específicas, como o Luz para Todos (em 2003) e o Prouni (Programa Universidade para Todos), em 2004. Segundo dados do governo federal, o Prouni atendia,no segundo semestre de 2006,47.057 estudantes com bolsas integrais e parciais, e o Luz para Todos, no início de 2007, 6,2 milhões de pessoas correspondendo a 1,2 milhão de ligações (a maioria na área rural do Nordeste). Por sua vez, além do impacto dos programas citados em suas clientelas específicas, certamente os indicadores econômicos positivos (inflação baixa, valorização do real, retomada do crescimento do PIB, aumento do emprego formal e do rendimento médio, etc.) exibidos no final do primeiro mandato do governo Lula lastreiam a expectativa otimista sobre o futuro do país e do progresso pessoal dos brasileiros, conforme se pode ver na tabela que se segue.

TABELA 3

Expectativa sobre a situação econômica do país e situação econômica pessoal [resposta estimulada e única \%]. Dezembro/2006

\begin{tabular}{|c|l|c|}
\hline \multirow{4}{*}{$\begin{array}{c}\text { Situação econômica } \\
\text { do país }\end{array}$} & Vai melhorar & 41 \\
\cline { 2 - 3 } & Vai piorar & 14 \\
\cline { 2 - 3 } & Vai ficar como está & 42 \\
\cline { 2 - 3 } & Não sabe & 3 \\
\hline \multirow{4}{*}{$\begin{array}{c}\text { Situação econômica } \\
\text { do entrevistado }\end{array}$} & Vai melhorar & 55 \\
\cline { 2 - 3 } & Vai piorar & 9 \\
\cline { 2 - 3 } & Vai ficar como está & 33 \\
\cline { 2 - 3 } & Não sabe & 3 \\
\hline & Total em \% & 100 \\
\hline
\end{tabular}


A percepção positiva sobre o futuro do país e as perspectivas econômicas pessoais se refletiu na avaliação do governo Lula, que chegou ao final do seu primeiro mandato com $85 \%$ de aprovação (ótimo, bom e regular) e apenas $14 \%$ de reprovação (ruim/ péssimo), como se pode ver na Tabela 4 .

Correlacionando-se os dois dados, é possível afirmar que, nesse contexto, a avaliação do desempenho do governo é uma variável dependente da percepção sobre a situação econômica pessoal e do país, e que o voto em 2006 tenha tido um forte componente de pragmatismo, especialmente quando lembramos que a campanha daquele ano foi marcada pelo chamado "escândalo do mensalão" explorado intensamente pela oposição e pela grande imprensa (este e outros aspectos da disputa eleitoral de 2006 serão abordados mais adiante).

\section{A situação nacional em 2010}

A economia brasileira, que vinha crescendo desde o fim da recessão, em 2003, retomou o crescimento acelerado em 2007 movido pela recuperação da renda dos setores assalariados, forte expansão do crédito e grande demanda por commodities pelo mercado internacional. Com a inflação sob controle (dentro da meta estabelecida pelo Banco Central), o crescimento do PIB fechou 2007 com 5,4\%, mantendo o fôlego nos anos seguintes (com exceção de 2009, quando a crise internacional desaqueceu a economia global). Em 2010, ano eleitoral, o PIB atingiu a marca dos 7,1\% (o maior da década) com a média do segundo mandato Lula $(4,5 \%)$ superando a do primeiro $(3,5 \%)$ e a do período FHC $(2,3 \%)$ e apenas um pouco abaixo da média de todo o período republicano $(4,55 \%)$.

Esse crescimento foi acompanhado pela queda na taxa de desemprego e pela diminuição da informalidade. Segundo o IBGE, em dezembro de 2010 a taxa de desemprego era de $5,4 \%$ da PEA, o menor resultado desde o início da série histórica iniciada em 2002 por aquele instituto. A média de desemprego no segundo mandato Lula foi da ordem de 6,7\%, também um recorde histórico, e o saldo de novos postos de trabalho formais (com carteira de trabalho assinada), considerando-se os dois mandatos, atingiu a casa dos 15 milhões de novas vagas. Por sua vez, o salário mínimo, considerando-se os dois mandatos, teve um aumento deflacionado de $54 \%$ do seu valor.

O resultado combinado de crescimento econômico e políticas sociais de distribuição direta de renda, como o Bolsa Família, produziu, ao longo dos oito anos do mandato Lula, dois efeitos diretos: redução da desigualdade de renda e o surgimento de uma nova classe média.

Segundo Neri (2010), a desigualdade de renda no Brasil vem caindo desde 2001. De acordo com o autor, "entre 2001 e 2009, a renda per capita dos $10 \%$ mais ricos aumentou em $1,49 \%$ ao ano, enquanto a renda dos mais pobres cresceu a uma notável taxa de $6,79 \%$ por ano" (Neri, 2010, p. 10). Ainda segundo Neri, a combinação entre crescimento e redução da desigualdade de renda atingiu o menor nível desde os anos 60,com o número de pobres caindo de 49 milhões, em 2003, para 28,8 milhões em 2009. O indicador mais preciso desse movimento é o índice de Gini que, em 1990, era de 0,6091 e, em 2009, reduziu-se para 0,5448.

Mas talvez o efeito mais notável tenha sido a intensa mobilidade social, entre 2003 e 2009, que catapultou cerca de 29 milhões de pessoas para a classe média (classe C). Esse novo segmento, somado às classes AB,

\section{TABELA 4 Avaliação do governo Lula. Dezembro/2006}

\begin{tabular}{|l|c|}
\hline \multicolumn{1}{|c|}{ Avaliação } & $\mathbf{2 0 0 6}$ \\
\hline Ótimo/bom & 52 \\
\hline Regular & 33 \\
\hline Ruim/péssimo & 14 \\
\hline Não Sabe & 1 \\
\hline Total & 100 \\
\hline
\end{tabular}

Fonte: Datafolha, I3/12/2006 


\section{TABELA 5}

\section{Preferência partidária [\%] pelo PT por estrato de renda familiar. Março/2011}

\begin{tabular}{|l|l|}
\hline \multicolumn{1}{|c|}{ Faixa de renda } & PT \\
\hline Até 2 SM (classe E) & 23 \\
\hline De 2 a 3 SM (classe D) & 28 \\
\hline De 3 a 5 SM (classe C) & 32 \\
\hline De 5 a 10 SM (classe AB) & 29 \\
\hline Mais de 10 SM (classe AB) & 16 \\
\hline
\end{tabular}

Fonte: Datafolha, |5-16/3/201|

forma um contingente que corresponde, hoje, a 50,5\% da população brasileira. Isso significa que, pela primeira vez, a classe média se torna a classe dominante não só em termos de consumo como do ponto de vista político, podendo, sozinha, decidir uma eleição. Contudo, essa "nova classe média" não assimilou automaticamente os valores e as preferências políticas da classe média tradicional $(\mathrm{AB})$, pois, como deixam claro os dados da Tabela 5 , é na classe C que o PT tem o seu apoio eleitoral mais firme.

TABELA 6

Opinião sobre a situação do país após oito anos de mandato. Comparativo governos fHC e Lula [\%]

\begin{tabular}{|l|c|c|}
\hline \multirow{2}{*}{ Categorias } & FHC & Lula \\
\cline { 2 - 3 } & $\mathbf{9}$ a 11/12/2002 & $\mathbf{1 7}$ a 19/11/2010 \\
\hline Melhor & 35 & 84 \\
\hline Igual & 28 & 12 \\
\hline Pior & 34 & 2 \\
\hline Não sabe & 3 & 1 \\
\hline
\end{tabular}

Fonte: Datafolha, I7/I I/2010
Por sua vez, os dados da Tabela 6 (avaliação comparativa dos mandatos de Lula e FHC) mostram, de modo claro, a conexão entre o desempenho econômico do governo e a avaliação positiva do eleitorado, reforçando a evidência de que o eleitor, tanto em 2006 quanto em 2010, votou com um olhar retrospectivo e com o bolso. Em resumo, repetindo a afirmação de Lewis-Beck: “Os bons tempos mantêm os partidos no poder...”.

\section{AS CAMPANHAS E A COBERTURA}

\section{DA MÍDIA: A AGENDA-SETTING DAS ELEIÇÕES DE 2006 E 2010}

\section{6}

O embate eleitoral de 2006 foi travado sob a sombra do escândalo do "mensalão", que veio à luz em meados de 2005 e monopolizou a atenção da mídia até dezembro daquele ano, quando o mandato de José Dirceu foi cassado. Mesmo com a CPI concluída e com os principais personagens do escândalo indiciados, o assunto continuou a ser explorado, em 2006, de forma intermitente, nas páginas de opinião da grande imprensa escrita, em geral com matérias críticas em relação ao comportamento ético do PT e do governo federal.

Portanto, a campanha eleitoral de 2006, polarizada desde o início entre Lula e Alckmin, com todos os outros candidatos situados abaixo do patamar de $10 \%$ das intenções de voto durante toda a corrida eleitoral, tinha como pano de fundo a questão ética e as acusações de corrupção do PT e do governo Lula.

As estratégias eleitorais dos dois principais candidatos obedeceram, como não poderia deixar de ser, à lógica do mandatário e do desafiante. No primeiro caso, Lula recorre aos dados positivos da economia e de seus programas sociais e compara diretamente o seu governo com 
o do antecessor (FHC). A ideia central, obviamente, é convencer o eleitor de que seu governo foi melhor do que os oito anos de gestão tucana e que governou para os mais pobres. Seu principal opositor, num primeiro momento, que podemos definir como a primeira fase da sua campanha, estrutura sua estratégia em dois eixos: apresentação da sua biografia política e administrativa (não era, então, um político nacionalmente conhecido) e o contraponto ao governo Lula de que poderia fazer mais e melhor através de uma gestão pública moderna. Os argumentos políticos nessa fase, portanto, estão num plano secundário e a disputa retórica se dá basicamente em torno de propostas setoriais e da comparação (pela campanha de Lula) do desempenho de gestões no passado (governo tucano) e presente (governo Lula) e na promessa de um futuro melhor através da continuidade (caso do Lula) ou da mudança (caso de Alckmin) de governo. Deve-se notar que o candidato tucano, nessa fase, evita caracterizar o "mundo presente" como ruim, estruturando a sua estratégia comunicativa na promessa de "mundo futuro" melhor. Em outras palavras, nessa fase o tucano evita atacar diretamente o governo e usar a campanha negativa como estratégia para enfrentar o mandatário.

Mas, como lembra Holbrook, os eventos políticos são variáveis importantes nos rumos da campanha. Em meados de setembro, um mês após o início do HGPE e a menos de três semanas da eleição, estoura o escândalo que a imprensa batizou de "dossiê tucano"3. Esse evento produziu duas consequências imediatas: mudou o rumo da estratégia eleitoral tucana que, entrando em nova fase, passou a explorar intensamente o episódio ligando-o ao escândalo do "mensalão", deslocando, dessa forma, o eixo da campanha para o terrenoético e para os ataques diretos; e reacendeu na grande imprensa as críticas de fundo ético contra o PT e a candidatura Lula. Desse modo, como lembra Azevedo (2008, p. 235), ocorreu um processo de retroalimentação entre o campo político, a partir da oposição, e o campo jornalístico, que terminou configurando a questão ética e a corrupção como o principal tema da agenda-setting no primeiro turno da eleição presidencial.

Como decorrência e como se pode comprovar (ver Tabela 7) nos dados do monitoramento realizado pelo Doxa/Iuperj (Aldé, Mendes \& Figueiredo, 2007,p. 77),
3 Prisão em flagrante de dois militantes do PT que,supostamente,estariam comprando um dossiê contra José Serra que, então, disputava o governo do estado em São Paulo

4 Valência: + (Positivo) matéria sobre ou com o candidato reproduzindo programa de governo; promessas; autodeclaração ou declarações do autor da matéria ou de terceiros (pessoas ou entidades) favoráveis (contendo avaliação de ordem moral, política ou pessoal) ao candidato; reprodução de ataques do candidato a concorrentes, pesquisas favoráveis. - ( $\mathrm{Ne}$ gativo): matéria reproduzindo ressalvas, críticas ou ataques (contendo avaliação de ordem moral, política ou pessoal) do autor da matéria, de candidatos concorrentes ou de terceiros a algum candidato, pesquisas desfavoráveis. N (Neutro) agenda do candidato, citação sem avaliação moral, política ou pessoal do candidato.

\section{TABELA 7}

\section{Valência4 [\%] de Lula nos três principais jornais do país. Eleições presidenciais de 2006 - $1^{\circ}$ turno [14/2 a 1\%/10/2006]}

\begin{tabular}{|l|c|c|c|c|c|c|c|c|c|c|c|c|}
\hline \multicolumn{1}{|c|}{ Jornais } & \multicolumn{3}{|c|}{ FSP } & \multicolumn{3}{c|}{ OESP } & \multicolumn{3}{c|}{ O Globo } \\
\hline Ano/valência & + & $\mathbf{N}$ & - & Saldo & + & $\mathbf{N}$ & - & Saldo & + & $\mathbf{N}$ & - & Saldo \\
\hline $\mathbf{2 0 0 6}$ (informação) & & & & & & & & & & & & \\
\hline Lula presidente & 25 & 40 & $\mathbf{3 5}$ & Negativo & 12 & $\mathbf{4 1}$ & $\mathbf{4 7}$ & Negativo & 11 & $\mathbf{4 6}$ & $\mathbf{4 3}$ & Negativo \\
\hline Lula candidato & 33 & 30 & $\mathbf{3 7}$ & Negativo & $\mathbf{2 4}$ & $\mathbf{2 6}$ & $\mathbf{4 3}$ & Negativo & 19 & 46 & $\mathbf{4 1}$ & Negativo \\
\hline $\mathbf{2 0 0 6}$ (opinião) & & & & & & & & & & & & \\
\hline Lula presidente & 12 & 39 & $\mathbf{4 9}$ & Negativo & 10 & $\mathbf{4 2}$ & $\mathbf{4 9}$ & Negativo & 8 & 45 & $\mathbf{4 7}$ & Negativo \\
\hline Lula candidato & 23 & $\mathbf{4 7}$ & $\mathbf{3 0}$ & Negativo & 16 & $\mathbf{2 4}$ & $\mathbf{6 0}$ & Negativo & $\mathbf{9}$ & $\mathbf{3 8}$ & $\mathbf{5 3}$ & Negativo \\
\hline
\end{tabular}


a cobertura eleitoral de 2006 pelos três maiores jornais do país foi, ao contrário de 2002, predominantemente negativa (especialmente nas páginas de opinião) para o candidato petista. Segundo os referidos autores,

“[...] o clima editorial brasileiro é desfavorável para o presidente e candidato Lula durante o ano eleitoral de 2006. [...] isso reflete uma cobertura jornalística que concede pouco espaço à agenda do governo e mostra-se crítica das políticas federais em várias frentes e com forte ênfase na questão da corrupção" (Aldé, Mendes \&Figueiredo, 2007, p. 79).

Acampanha e a agenda negativa, exacerbada com o episódio do escândalo do dossiê, impediram a vitória de Lula, que liderou todas as pesquisas de intenção de voto ao longo do ano, ainda no primeiro turno. No segundo turno, a campanha de Lula mudou a agenda eleitoral ao politizar o debate em torno do tema da privatização (novamente confrontando as gestões Lula $x$ FHC e acusando os tucanos de "privatistas"). A campanha tucana, em ascensão desde o episódio do dossiê (dados do Datafolha mostram que entre 22/8 e 30/9 a intenção de voto em Alckmin passou de $25 \%$ para $35 \%$ e Lula recuou de $49 \%$ para $46 \%$ ), adotou uma postura excessivamente defensiva na disputa retórica com os petistas em torno desse tema. Na defensiva, e com o escândalo do dossiê esgotado do ponto de vista da sua exploração política, a candidatura Alckmin entrou em declínio até terminar o segundo turno com uma votação abaixo da do primeiro.

\section{0}

A eleição de 2010 foi a primeira, desde a volta das eleições presidenciais, em que Lula estava fora da disputa eleitoral.

Contudo, como todos recordam, embora não pudesse participar como candidato, Lula assumiu na campanha o papel de principal
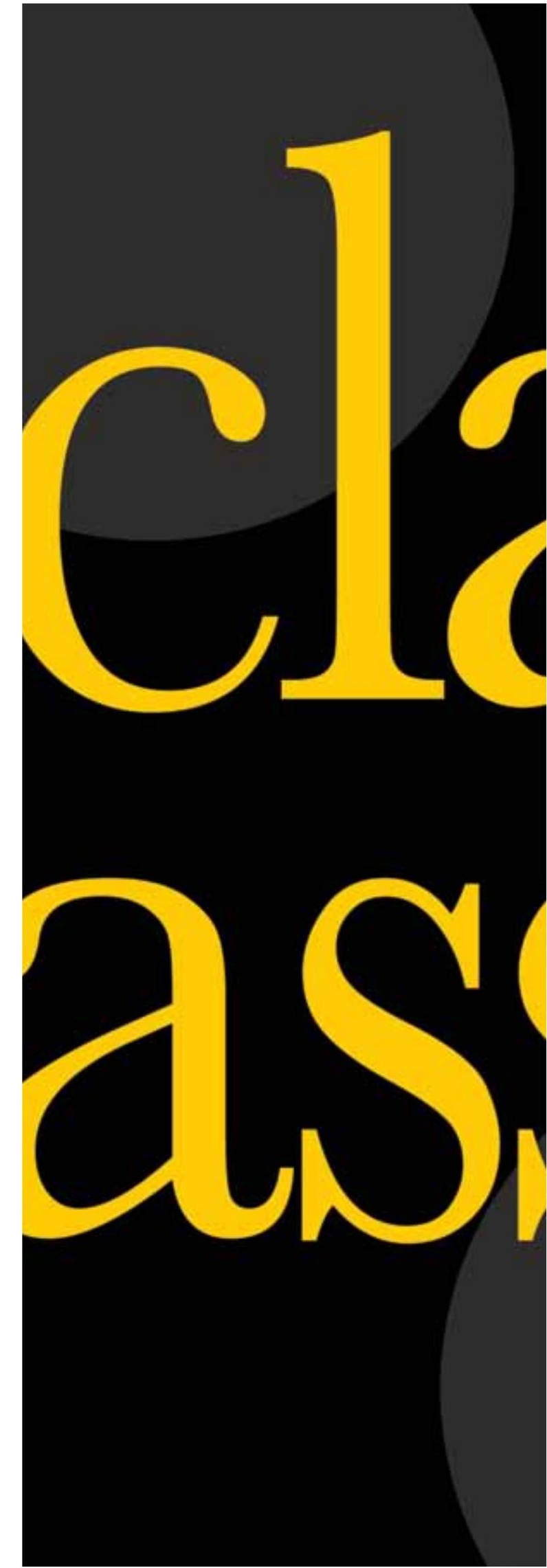


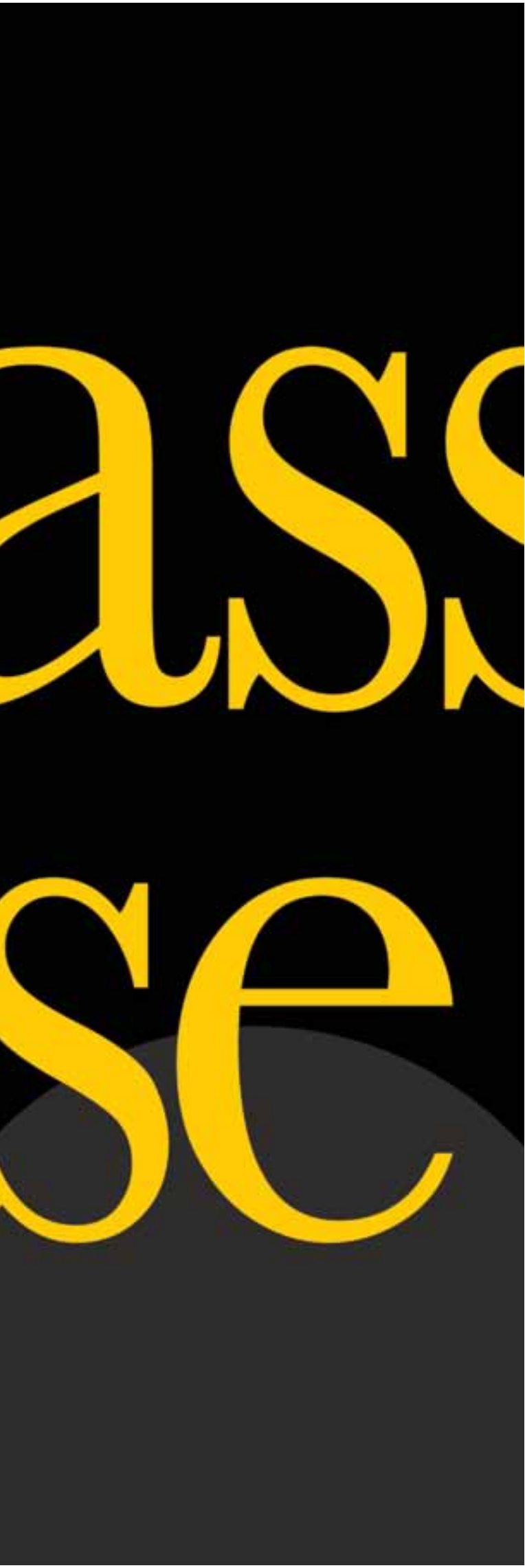

patrocinador e fiador da candidata do campo governista que, até então, não tinha disputado nenhuma eleição. Portanto, a estratégia governista foi, numa primeira etapa, associar o nome de Lula (que estava terminando o governo com inéditos $80 \%$ de aprovação pessoal) e Dilma com o objetivo de tornar conhecido o nome da candidata e vinculá-la aos sucessos do governo Lula. Numa segunda etapa, Lula iria para o segundo plano,e seriam apresentados aos eleitores os programas de governo tendo como principal apelo eleitoral o Programa de Aceleração do Crescimento (PAC). O eixo central da estratégia de comunicação da campanha foi, reeditando de forma ampliada a tática de 2006 de comparar as gestões Lula $x$ FHC, 0 discurso da continuidade ancorada em três argumentos centrais: os números positivos da economia, que em 2010 apresenta forte crescimento; os programas sociais e a redução da desigualdade e a forte mobilidade social, que ascendeu quase trinta milhões de pessoas para a classe média. Em resumo, a estratégia comunicativa vendia um mundo presente bom cuja permanência no futuro dependia da continuidade do governo.

O campo da oposição foi liderado pela candidatura tucana de José Serra, mas, ao contrário de 2006, contou com outra candidatura competitiva, que foi a de Marina Silva, do PV, que terminaria a corrida eleitoral no primeiro turno com 19,33\% dos votos.

A estratégia comunicativa do candidato tucano também dividiu-se em duas fases distintas. Na primeira, a ideia central era posicionar Serra como o candidato "pós-Lula", evitando criticar um presidente popular e um governo bem-avaliado e polarizando diretamente com Dilma. O argumento retórico principal nessa estratégia valorizava a biografia política e administrativa de Serra e apontava para os riscos de eleger uma candidata "desconhecida" e sem passado eleitoral nem mandatos eletivos. Traduzindo essa estratégia para o esquema dos mundos possíveis, Serra reconhecia um mundo presente bom (e, nesse sentido, recusava o papel clássico de oposicionista) e se apresentava como o único candidato capaz de preservar as conquistas do presente e avançar mais 
Os eventos referem-se à quebra de sigilo do imposto de renda de políticos tucanos e da filha de Serra e às acusações de lobby na Casa Civil. no futuro. Essa estratégia, criticada internamente por aliados pela sua natureza acrítica, revelou-se inócua à medida que Dilma crescia nas intenções de voto e abria uma larga vantagem em relação a Serra $(51 \%$ a 27\%, Datafolha de 13-15/9/10). Contudo, como em 2006, novos eventos políticos (vazamento de dados sigilosos pela Receita Federal e o caso Erenice Guerra $)^{5}$ mudam os rumos da campanha e a previsão de uma vitória de Dilma no primeiro turno, e abrem caminho para a campanha negativa e a desconstrução da imagem da candidata governista.Acampanha serrista sofre, nesse momento, uma inflexão em sua estratégia e assume uma posição mais dura e crítica, acusando o governo de corrupção e práticas eticamente condenáveis, numa reedição da tática empregada por Alckmin em 2006. Quando as denúncias de quebra de sigilo e do caso Erenice começam a arrefecer na atenção da mídia e da opinião pública, a campanha tucana passa a explorar, usando basicamente a Internet, temas morais (a questão do aborto e da união civil entre pessoas do mesmo sexo) e religiosos (ateísmo $x$ fé) introduzidos por sites, blogs e Twitter, que acusavam a candidata petista de ambiguidade em relação a tais questões .

A partir dessa inflexão, a campanha se torna acirrada e nervosa, com diversos eventos polêmicos de grande repercussão na blogosfera e nas novas ferramentas de comunicação digital (Facebook, Twitter, etc.). Os efeitos eleitorais, porém, beneficiam Serra apenas indiretamente (levando-o para o segundoturno), pois enquanto Dilma perdia intenção de votos, que duas semanas antes da eleição lhe dava vitória no primeiro turno, a principal beneficiária terminou sendo Marina Silva, que, na condição de tertius, terminou com uma expressiva votação e forçou a realização do segundo turno. A segunda rodada eleitoral impeliu o confronto direto entre os projetos políticos dos candidatos finalistas. A campanha de Dilma, aproveitando os ventos favoráveis da economia, retomou e reforçou a comparação entre os governos Lula e FHC, ressuscitou o tema dos riscos das privatizações (com foco no Pré-Sal) e enfatizou o combate à miséria. Por sua vez, a campanha de Serra retomou a comparação da biografia política e administrativa entre os dois candidatos e explorou as questões ligadas às políticas setoriais, especialmente na área da saúde, concentrando seus ataques no plano político, na acusação de partidarização e inchaço da máquina do Estado.

Nesse contexto, a cobertura dos grandes jornais foi, de modo geral, mais equilibrada (com exceção do Estadão, que declarou em editorial apoio formal a Serra) do que no pleito anterior de 2006, conforme se pode ver na Tabela 8 . Contudo, mesmo assim, ainda ligeiramente negativa para a candidata petista. Porém, deve-se observar que os dados da referida tabela compreendem

\section{TABELA 8}

\section{Valência [\%] de Serra e Dỉma nos três principais jornais do país. Eleições presidenciais de 2010 [16/2 a 31/10/2010]}

\begin{tabular}{|l|c|c|c|c|c|c|c|c|c|c|c|c|}
\hline Jornais & \multicolumn{4}{|c|}{ FSP } & \multicolumn{4}{|c|}{ OESP } & \multicolumn{3}{c|}{ O Globo } \\
\hline Valência & + & $\mathbf{N}$ & - & Saldo & + & $\mathbf{N}$ & - & Saldo & + & $\mathbf{N}$ & - & Saldo \\
\hline Dilma & 36 & 28 & $\mathbf{3 7}$ & Negativo & 30 & 38 & $\mathbf{3 2}$ & Negativo & 41 & 24 & $\mathbf{3 5}$ & Positivo \\
\hline Serra & 32 & 31 & $\mathbf{3 7}$ & Negativo & 37 & 39 & $\mathbf{2 4}$ & Positivo & 42 & 26 & $\mathbf{3 2}$ & Positivo \\
\hline
\end{tabular}

Fonte: planilha do Doxa-Uerj compilada pelo autor. A categoria "neutro" agrega também os números da categoria "equilibrado", que consta originalmente na planilha. Os dados abrangem as páginas de opinião e informação 
tanto as matérias das páginas informativas (noticiário e reportagens) quanto as opinativas (nas quais o jornal e seus articulistas expressam livremente suas opiniões através de editoriais, artigos e colunas). Nessas últimas, um exame mais detalhado mostraria que, nos três veículos aqui considerados, prevaleceu uma posição crítica em relação ao governo liderado pelo PT e ao próprio presidente (especialmente por sua participação na campanha e pelo suposto uso eleitoral da máquina do governo) e de desconfiança em relação à sua candidata, que foi enxergada, de modo dominante, como uma "criatura" política de Lula e, portanto, sem autonomia e luz própria, ao contrário de Serra, avaliado como dono de uma biografia política e administrativa consistente. Em resumo, o clima editorial dos grandes jornais, em 2010, permaneceu desfavorável para as forças governistas, ainda que isso não se traduzisse num engajamento direto e aberto na candidatura oposicionista, com a mencionada exceção do Estadão e, no segmento das revistas semanais, não analisadas aqui, da revista Veja.

\section{CONSIDERAÇÕES FINAIS}

As eleições presidenciais de 2006e 2010, embora disputadas em momentos e com candidatos diferentes, se realizaram num contexto em que o ambiente econômico foi claramente favorável ao governo em ambos os pleitos. Isso foi particularmente importante em 2006, quando o cenário político se apresentava turvado pelo "escândalo do mensalão" e adverso à reeleição de Lula. Em 2010, embora com um cenário político mais desanuviado, pela primeira vez Lula estava fora do processo eleitoral, e o governo postulava sua continuidade com uma candidata neófita e sem nenhuma experiência eleitoral anterior contra o principal candidato da oposição, que tinha em seu currículo larga experiência política e administrativa. Como todos sabemos, apesar dos handicaps nos cenários políticos, os candidatos petistas terminaram triunfando nos dois pleitos.
Portanto, tanto em 2006 quanto em 2010, o ambiente econômico predominou sobre o cenário político favorecendo o "voto econômico" e confirmando a premissa de Lewis-Beck de que os bons tempos mantêm os partidos no governo. Como se viu ao longo deste artigo, os grandes responsáveis pelo voto governista foram os eleitores com renda abaixo de dez salários mínimos, ou seja, os segmentos populares e a chamada "nova classe média", cuja decisão eleitoral foi tomada a partir do "voto retrospectivo" que premiou a gestão Lula.

As campanhas petistas e tucanas adotaram, tanto em 2006 quanto em 2010, estratégias eleitorais e comunicativas baseadas em agendas distintas. O PT mirou a nova classe média e os estratos populares explorando o crescimento e a sensação de bem-estar econômico, os programas sociais e o combate à miséria e a redução da desigualdade. O PSDB adotou, em 2006, o discurso da eficiência na gestão pública e, principalmente, os temas éticos centrados no combate à corrupção. Em 2010, centrou seu discurso na biografia do candidato e na sua experiência e capacidade técnica e retomou, num segundo momento, os temas éticos da campanha de 2006 e as questões de natureza moral e religiosa (aborto, fé religiosa, etc.). Em resumo, a estratégia petista ancorou, em ambas as disputas, sua agenda de campanha na economia ("É a economia, estúpido!") e os tucanos, no plano político-administrativo e ético.

Por sua vez, a agenda nas páginas opinativas dos grandes jornais, que têm no público AB sua principal audiência, privilegiou as questões éticas em 2006 (num processo de retroalimentação do discurso oposicionista) e, em 2010, manteve no essencial sua postura crítica em relação ao governo, ao PT e ao presidente Lula, privilegiando a pauta política e cultural (questão da religiosidade e do aborto) em detrimento da econômica, que era mais favorável às hostes governistas Assim, em nenhum dos dois pleitos o governo contou com o apoio dos grandes jornais ou com uma agenda da mídia favorável.

Tomando-se os contextos da competição eleitoral de 2006 e de 2010, as vitórias de 
Lula e de Dilma só podem ser entendidas a partir da hipótese da clivagem de classe (dada pela discrepância entre os votos das classes AB e CDE) e do predomínio da agenda econômica (e do voto pragmático) proposta pelos governistas sobre as agendas político-administrativas e éticas dos candidatos tucanos.

Finalmente, coloca-se em xeque o velho consenso da literatura da área de comunicação política de que a grande imprensa é um grande eleitor e fazedor de presidente. Com a fragmentação da mídia, que ampliou a informação (através de sites, blogs, etc.) e segmentou a audiência, e a dissociação da agenda da "nova classe média" edos segmentos populares da classe AB, a influência da grande imprensa se restringiu ao seu público leitor por excelência, ou seja, às classes altas e média tradicional, mais sensíveis às questões éticas, e cuja opinião é formatada e/ou reverberada pelos grandes jornais.

\section{BIBLIOGRAFIA}

ABRÚCIO, F.; LOUREIRO, M. R. O Estado numa Era de Reformas: os Anos FHC - Parte 1. Brasília, MP/ Seges, 2002.

ALDÉ, A.; MENDES, G.; FIGUEIREDO, M. "Imprensa e Eleições Presidenciais: Natureza e Consequências da Cobertura das Eleições de 2002 e 2006", in Venício A. de Lima (org.). A Mídia nas Eleições de 2006. São Paulo, Fundação Perseu Abramo, 2007, pp. 65-87.

ALMEIDA FILHO, N.; SOUZA, L. R. "A Busca pela Estabilidade Econômica e seus Efeitos sobre o Projeto Fome Zero no Brasil" (paper), in XLIV Congresso da Sober. Fortaleza, 2006.

ALMEIDA, J. "Evolução de Imagem do Governo Lula e Comportamento Eleitoral em 2006", in Política \& Sociedade, no 10, abril de 2007, pp. 117-52.

AZEVEDO, F. A. "O PT, a Imprensa e as Coberturas das Eleições Presidenciais (1989-2006)", in Vitor Amorim de Angelo e Marco Antonio Villa (orgs.). O Partido dos Trabalhadores e a Política Brasileira (1980-2006). São Carlos, Edufscar, 2009.

CARREIRÃO, Y. "A Eleição Presidencial Brasileira de 2006: uma Análise Preliminar", in Política \& Sociedade, no 10, abril de 2007, pp. 91-116.

COIMBRA, M. "A Mídia Teve Algum Papel Durante o Processo Eleitoral de 2006?", in Venício A. de Lima (org.). A Mídia nas Eleições de 2006. São Paulo, Fundação Perseu Abramo, 2007.

DOWNS, A. An Economic Theory of Democracy. Nova York, Harper and Row, 1957.

FIGUEIREDO, M.; ALDÉ, A.; DIAS, H.; JORGE, V. L. Estratégia de Persuasão em Eleições Majoritárias: uma Proposta Metodológica para o Estudo da Propaganda Eleitoral. Rio de Janeiro, luperj, 1998.

FIGUEIREDO, M. "Intenção de Voto e Propaganda Política: Efeitos da Propaganda Eleitoral", in Logos 27, Mídia e Democracia, Ano 14, 2º semestre/2007, pp. 9-20.

FIORINA, M. P. Retrospective Voting in American National Elections. New Haven, Yale University Press, 1981.

HOLBROOK, T. M. Do Campaigns Matter?. London, Sage Publications, 1966.

KEY, V. O. The Responsible Electorate: Rationality in Presidential Voting, Cambridge, Harvard University Press, 1967.

LAVAREDA, A. Emoções Ocultas e Estratégias Eleitorais. Rio de Janeiro, Objetiva, 2009.

LEWIS-BECK, S. Economics and Elections. Ann Arbor, University of Michigan Press, 1988. 
MANCINI, P. "Mass Media Fragmentation:The End of Liberal Journalism?", 2011 (http://reutersinstitute.politics.ox.ac.uk/about/news/item/article/ media-fragmentation-the-end-of-lib.html).

MANIN, B. "As Metamorfoses do Governo Representativo", in Revista Brasileira de Ciências Sociais, n. 29, out./1995, pp. 5-34.

McCOMBS, M. A Teoria da Agenda - A Mídia e a Opinião Pública. Petrópolis, Vozes, 2009.

METTENHEIM, K. "A Presidência e a Separação de Poderes no Brasil - 1999-2002 (2003)", in Tempo Social, pp. 237-68.

MUNDIM, P. S. "A Cobertura da Imprensa e o Realinhamento Eleitoral de 2006", in IV Congresso Latino-Americano de Opinião Pública da Wapor. Belo Horizonte, 2011 (paper).

NERI, M. C. A Nova Classe Média: o Lado Brilhante dos Pobres. Rio de Janeiro, FGV/lbre, 2010.

RAE, D.; TAYLOR, M. The Analysis of Political Cleavages. New Haven, Yale University Press, 1970.

SARTORI, G. Partidos e Sistemas Partidários. Rio de Janeiro/Brasília, Zahar/Editora Universidade de Brasília, 1983.

ZUCCO JR., C. “Um Voto Pragmático”, in O Globo, 7/11/2006, p. 7. 